\title{
Hypospadias Repair and Its Complications at the Plastic Surgery Department, Khoula Hospital
}

\author{
Adel Hashish, Amal Al Balushi, Karim Haridi, Said Al-Busaidi \\ Khoula Hospital, Muscat, Oman \\ Email:amel.albulushi@gmail.com
}

How to cite this paper: Hashish, A., Al Balushi, A., Haridi, K. and Al-Busaidi, S. (2017) Hypospadias Repair and Its Complications at the Plastic Surgery Department, Khoula Hospital. Modern Plastic Surgery, 7, 13-19.

https://doi.org/10.4236/mps.2017.72002

Received: April 12, 2017

Accepted: April 25, 2017

Published: April 28, 2017

Copyright (c) 2017 by authors and Scientific Research Publishing Inc. This work is licensed under the Creative Commons Attribution International License (CC BY 4.0).

http://creativecommons.org/licenses/by/4.0/

\begin{abstract}
This study reviewed the complications associated with hypospadias repair surgery done at Khoula hospital, Oman during the period of January, 2010 to October, 2015. During this period, 178 cases were operated. Snodgrass and Bracka's techniques were the most used techniques. Complications were noted in 16 out of 82 patients operated using Snodgrass technique and 2 out 10 patients operated via Bracka's technique. This study helped in shifting the practice towards the technique associated with the lowest complications. As a result we adopted for our practice MAGPI for glandular hypospadias, Snodgrass for any type of hypospadias without chordee and Bracka's two stages repair for hypospadias with chordee.
\end{abstract}

\section{Keywords}

Hypospadias, Post-Operative, Complications, Bracka's, Snodgrass

\section{Introduction}

Hypospadias repair is a surgery that is associated with several complications. There are many surgical techniques used for the correction of hypospadias. This study investigates the complications associated with this surgery at our institution. We are using specific techniques at our institution, most commonly Snodgrass and Bracka's techniques. This paper is looking specifically at the complications associated with the techniques used at our institution. Reporting our complications and the surgical technique associated with complications will help us to prevent future complications and adopt the technique associated with the least complications.

There are many factors that affect the results of hypospadias repair. These 
factors include grade of hypospadias, technique of repair, skill of the surgeon, etc. [1]. There are controversies regarding the technique as well as timing of repair. American academy of paediatrics (1996) recommended early repair of hypospadias. While Bracka recommends age of 3 years for improved cooperation of the patient as the child would be more mature [2]. It is important to prevent complications in the first operation as managing complications is difficult with increased possibility of several surgeries to correct the complications [3]. This study reviews the complications to know which surgical technique we are more skilful in. It will also help us to adopt the best surgical technique to practice.

\section{Methods}

The study was done retrospectively. It included all patients with hypospadias operated at our unit at Khoula Hospital between the periods of 1st of January, 2010 until 15 October, 2015. Patient's data was extracted from the hospital “Al Shifa 2" system (Khoula Hospital). The data was framed on "Microsoft Excel 2010". Then it was analyzed using the "Statistical Package for Social Sciences (SPSS) version 19 for Windows.

The main aim of this study is to evaluate our techniques and look at the complications. By knowing that, we intend to adopt the surgical technique that is associated with least complications. Complications include early and late post operative complications such as hematoma, bleeding, infection, meatal stenosis, fistula, dehiscence, and surgery failure. This study serves as a feedback to our current practices and the best technique of repair. In addition to knowing some of the factors that might affect the results of the repair.

\section{Results}

The following graphs and columns are showing the analysis of the operated cases from January 2010 to October 2015. 178 surgical procedures were done at our centre. Figure 1 shows the surgical techniques used at our centre and the percentage of usage.

Our series showed an incidence of $18.52 \%$ (16 patients out of 82) complication rate for Snodgrass technique. Meatal stenosis occurred in 7 of 82 patients (8.64\%), Fistula in 4 patients (4.94\%), wound dehiscence in 2 patients $(2.46 \%)$, Failure of repair in 1 patient (1.23\%) and infection in 1 patient (1.23\%). Among the 7 cases of meatal stenosis only 3 cases needed meatal dilatation. The remaining 4 cases were insignificant and asymptomatic (Figure 2).

There were a number of re-operated (complicated) cases which were operated before at another centre which showed a complication rate of $50 \%$ ( 2 cases out of 4). One of them had a fistula and one had failure of repair (Figure 3).

Ten cases were operated using Bracka's technique. Five cases had no complications. Fistula appeared in three cases while bleeding occurred in two cases (Figure 4).

Fistula closure was done for 6 cases which were operated before at another hospital. One case only had a recurrence of the fistula (Figure 5). 
A. Hashish et al.

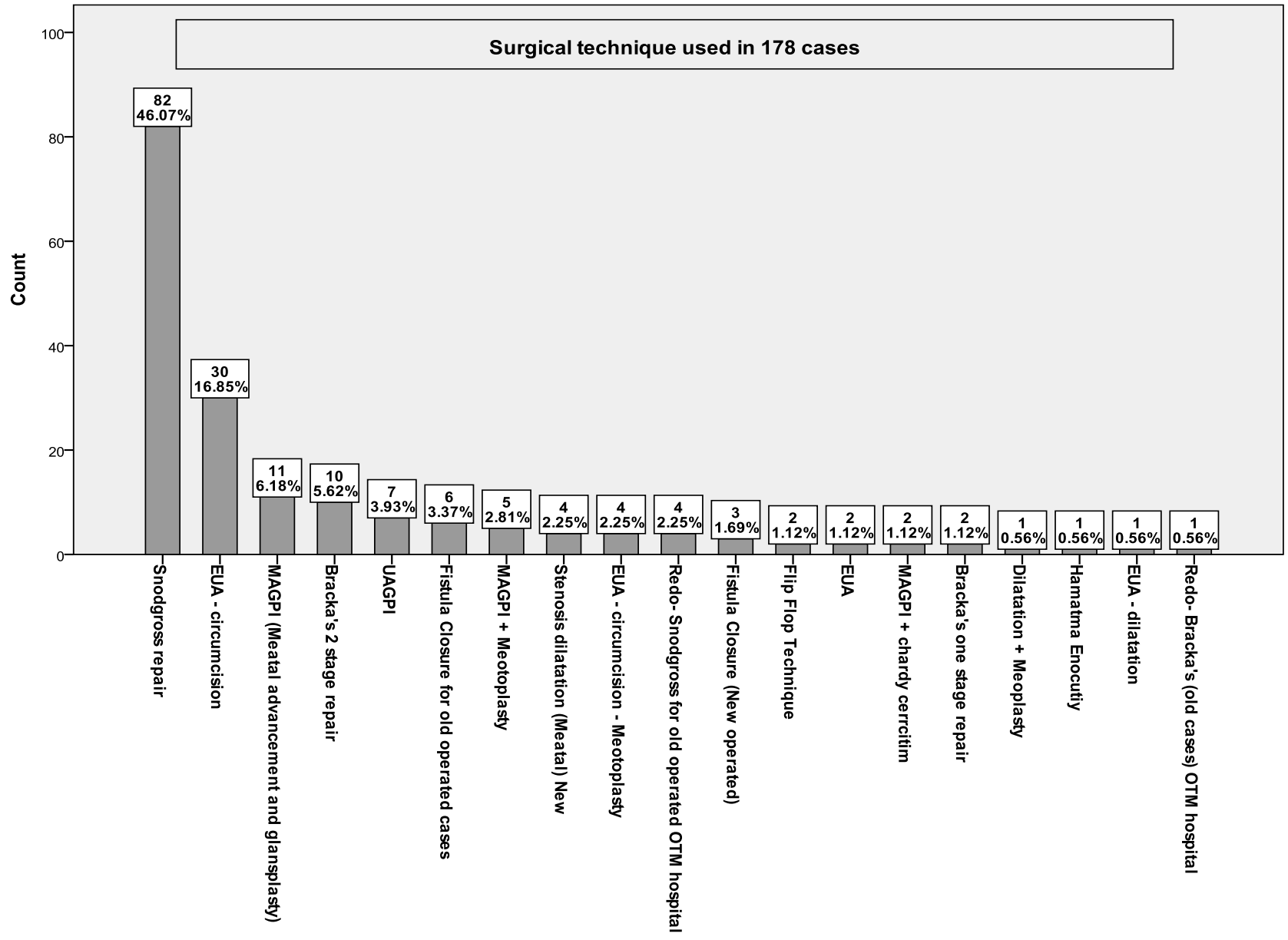

Figure 1. Surgical technique.

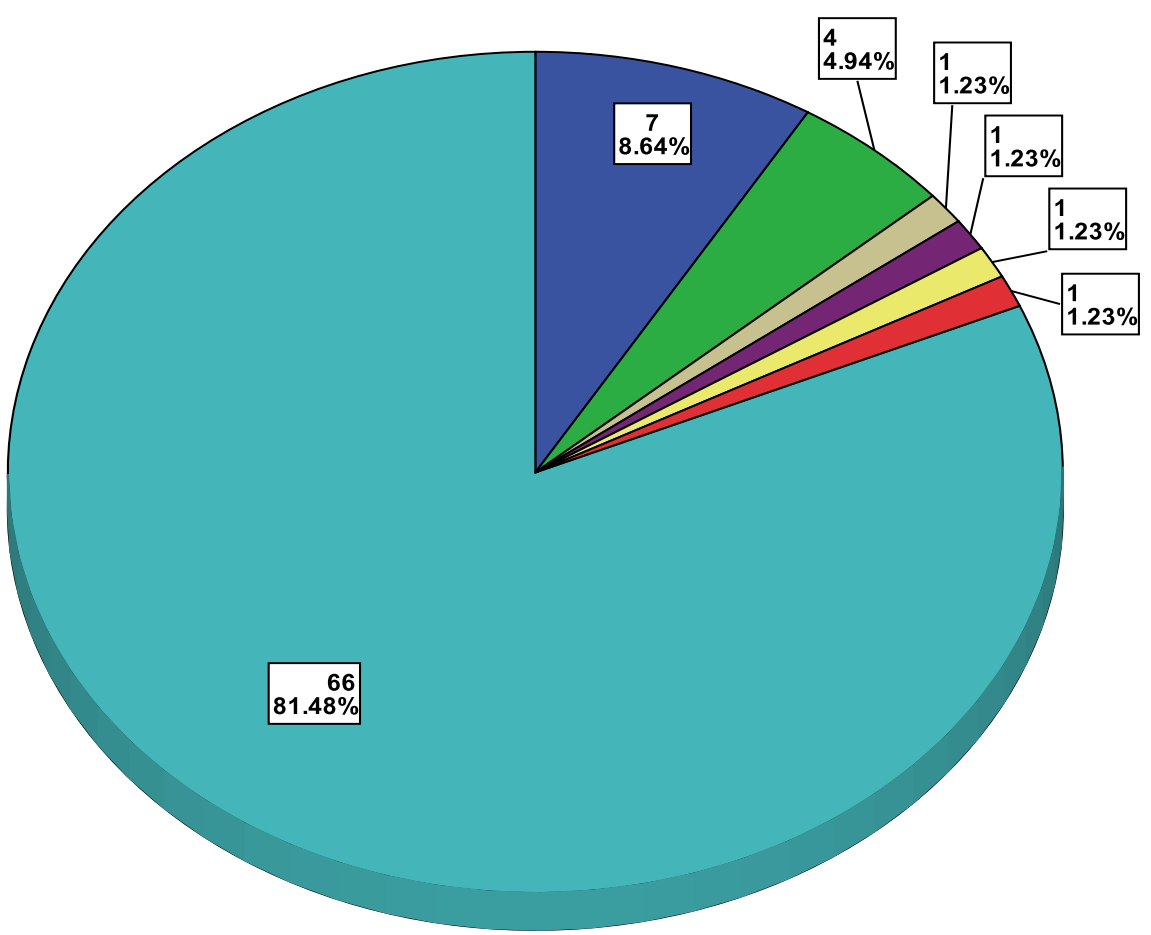

Post-op Complications

$\square$ Stenosis

$\square$ Fistula

$\square$ Dehiscence at the gland

Wound dehiscence

(Megauretma)

$\square$ Failure

$\square$ Infection

$\square$ No complications

Figure 2. Post-op complications observed after 82 operated cases using Snodgrass technique. 


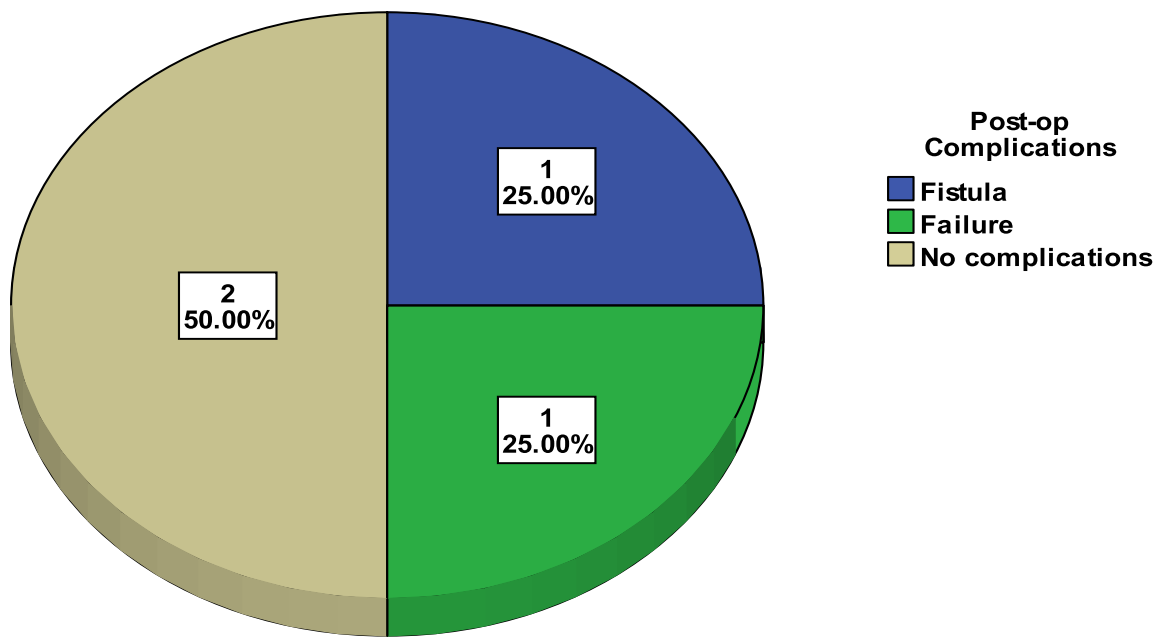

Figure 3. Post-op complications observed after 4 operated cases of Re-do Snodgrass of old operated cases at another hospital.

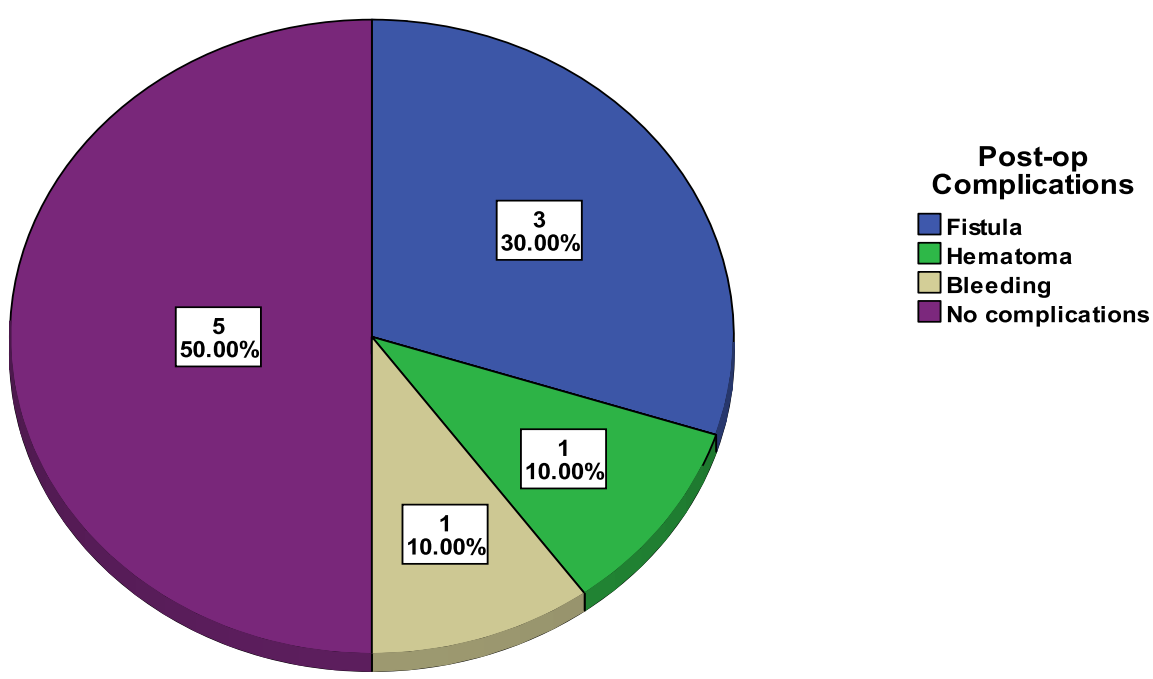

Figure 4. Post-op complications observed after 10 cases operated using Bracka's 2 stage repair.

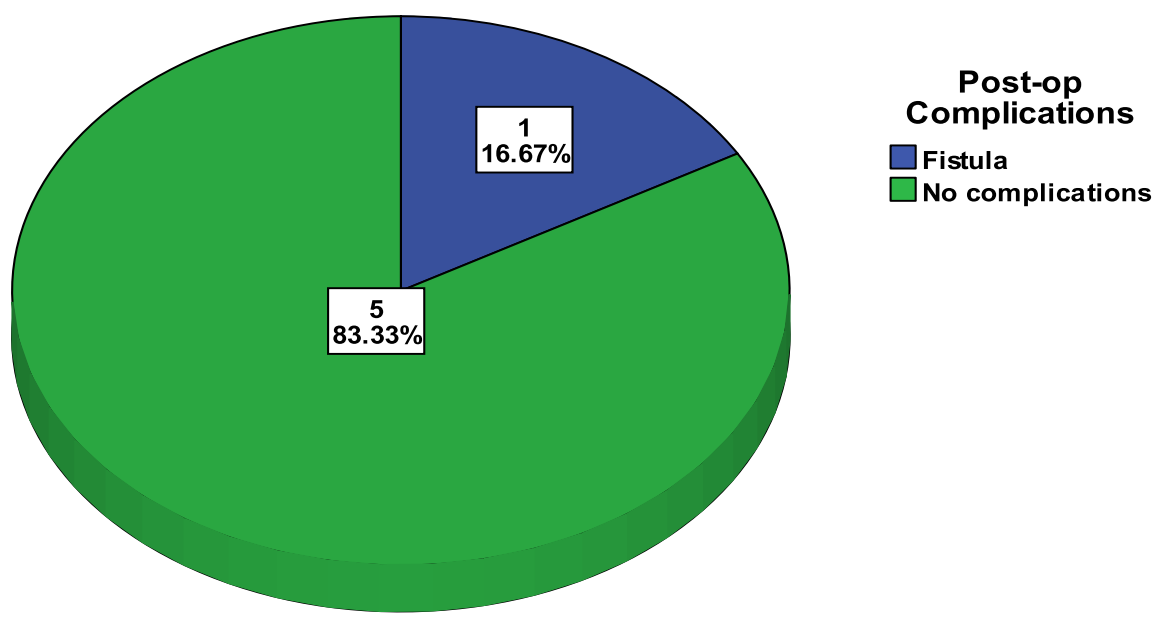

Figure 5. Post-op complications observed after 6 operated cases of fistula closure of old operated cases at another hospital. 


\section{Discussion}

There are many controversies in the management of hypospadias in the timing of repair as well as the surgical techniques used. With regard to timing, American academy of paediatrics (1996) recommended early repair of hypospadias when the child is 6 - 12 months of age. The reason for that is that there is significant psychological morbidity, including aberrant behaviour, guilt, and gender identity confusion with late repair [4]. The reason for Bracka to suggest delay of treatment until 3 years of age is that the child would be out of nappies and more cooperative [2].

With regard to surgical technique there are advancement techniques, tubularization, and flap techniques. The most common surgical procedures in practice are Snodgrass, Matheiw, Duckett, Asopa, Onlay flay, Bracka, Byars.

Post-hypospadias complications can be divided into immediate and long term. Immediate complications include bleeding, local edema and infection. Long term complications like fistula, meatal stenosis, stricture, diverticula and hair in the urethra. Cripples of the repair include multiple repairs, recurrent fistulae, persistent chordee and multiple strictures.

In our study, we included cases we operated in our unit from January 2010 to October 2015. During the period of study, we analyzed post-op complications. We noticed that the incidence of complications when we do UAGPI is relatively high so we stopped doing this procedure. As regard to Snodgrass we have satisfactory results and its complications' incidence is within normal range. Even at the end of the study we decided to shift the technique to Snodgraft as it showed better results. It also solved the problem of meatal stenosis. Data of Snodgraft procedure was not included in this study.

A prospective randomized study showed no influence of suture technique on outcomes of tabularized incised plate urethroplasty [5]. Another Prospective study showed increased likelihood of post-operative complications with increase in GMS scoring [6]. It includes 4 unit scale in each component: G-Glans size glans size/urethral plate quality, M-Meatal location, and S-degree of Shaft curvature, with more unfavourable characteristics assigned higher scores.

A study done by Schneuer and others included 285 boys found that there is no difference in complication post-repair between children who had repair between $0-18$ months and after 18 months of age [7]. While a study done in Italy suggests 8 - 12 months as ideal age [8]. Most complications occurred after 1 year and up to 5 years [7] [9]. A study done in Proximal hypospadias repair using a staged approach using transposed preputial skin flaps showed a complication rate of $68 \%$ (38 patients out of 56) [10]. While using dartos flaps in another study yielded overall complication rate of 9.3\% [11]. Snodgrass and others compared the urethroplasty and skin complications between patients undergoing distal TIP and prepucioplasty versus circumcision. Urethroplasty complications occurred in 30 out of $343(8.7 \%)$ circumcision patients versus 7 out of 85 patients $(8.0 \%)$ after prepucioplasty. Skin complications resulting in reoperation occurred in 7 (2.0\%) circumcision patients and $2(2.3 \%)$ prepucioplasty patients [12]. 


\section{Conclusion}

After reviewing of our data, analyzing and looking at our experience, our results were satisfactory and comparable to international standards. As a result we have standardized our procedure at our unit as follows: MAGPI for cases of glandular hypospadias, Snodgrass one stage repair for any type of hypospadias without chordee, Bracka's two stages repair for hypospadias with chordee. We recommend a follow-up study for the Snodgraft technique that we have recently adopted.

\section{References}

[1] Spinoit, A., Poelaert, F., Hoebeke, P., Snodgrass, W., et al. (2014) Duration of Follow-Up to Diagnose Hypospadias Urethroplasty Complications. Journal of Pediatric Urology, 10, 783-784. https://doi.org/10.1016/j.jpurol.2014.04.019

[2] Bracka, A. (1995) A Versatile Two-Stage Hypospadias Repair. Journal of Plastic, Reconstructive \& Aesthetic Surgery, 48, 345-352. https://doi.org/10.1016/s0007-1226(95)90023-3

[3] Myers, J.B., McAninch, J.W., Erickson, B.A. and Breyer, B.N. (2012) Treatment of Adults with Complications from Previous Hypospadias Surgery. Journal of Urology, 188, 459-463. https://doi.org/10.1016/j.juro.2012.04.007

[4] American Academy of Pediatrics (1996) Timing of Elective Surgery on the Genitalia of Male Children with Particular Reference to the Risks, Benefits, and Psychological Effects of Surgery and Anesthesia. Pediatrics, 97, 590-594.

[5] Sarhan, O., Saad, M., Helmy, T. and Hafez, A. (2009) Effect of Suturing Technique and Urethral Plate Characteristics on Complication Rate Following Hypospadias Repair: A Prospective Randomized Study. Journal of Urology, 128, 682-686. https://doi.org/10.1016/j.juro.2009.04.034

[6] Arlen, A.M., Kirsch, A.J., Leong, T., Broecker, B.H., Smith, E.A. and Elmore, J.M. (2015) Further Analysis of the Glans-Urethral Meatus-Shaft (GMS) Hypospadias Score: Correlation with Postoperative Complications. Journal of Paediatric Urology, 11, 71.e1-71.e5. https://doi.org/10.1016/j.jpurol.2014.11.015

[7] Schneuer, F.J., Holland, A.J., Pereira, G., Bower, C. and Nassar, N. (2015) Prevalence, Repairs and Complications of Hypospadias: An Australian Population-Based Study. Archives of Disease in Childhood, 100, 1038-1043. https://doi.org/10.1136/archdischild-2015-308809

[8] Marrocco, G., Vallasciani, S., Fiocca, G. and Calisti, A. (2004) Hypospadias Surgery: A 10-Year Review. Pediatric Surgery International, 20, 200-203. https://doi.org/10.1007/s00383-004-1147-1

[9] Snodgrass, W., Villanueva, C. and Bush, N.C. (2014) Duration of Follow-Up to Diagnose Hypospadias Urethroplasty Complications. Journal of Pediatric Urology, 10, 208-211. https://doi.org/10.1016/j.jpurol.2013.11.011

[10] Stanasel, I., Le, H.K., Bilgutay, A., Roth, D.R. and Gonzales, E.T. (2015) Complications Following Staged Hypospadias Repair Using Transposed Preputial Skin Flap. Journal of Urology, 194, 512-516. https://doi.org/10.1016/j.juro.2015.02.044

[11] Thomas, D.T., Cerit, K.K., Yener, S. and Kandirici, A. (2015) The Effect of Dorsal Dartos Flaps on Complication Rates in Hypospadias Repair: A Randomised Prospective Study. Journal of Pediatric Urology, 11, 23.e1-23.e4. https://doi.org/10.1016/j.jpurol.2014.07.010

[12] Snodgrass, W., Dajusta, D., Villanueva, C. and Bush, N. (2013) Foreskin Recon- 
struction Does Not Increase Urethroplasty or Skin Complications after Distal TIP Hypospadias Repair. Journal of Pediatric Urology, 9, 401-408.

https://doi.org/10.1016/j.jpurol.2012.06.008

Submit or recommend next manuscript to SCIRP and we will provide best service for you:

Accepting pre-submission inquiries through Email, Facebook, LinkedIn, Twitter, etc. A wide selection of journals (inclusive of 9 subjects, more than 200 journals)

Providing 24-hour high-quality service

User-friendly online submission system

Fair and swift peer-review system

Efficient typesetting and proofreading procedure

Display of the result of downloads and visits, as well as the number of cited articles

Maximum dissemination of your research work

Submit your manuscript at: http://papersubmission.scirp.org/

Or contact mps@scirp.org 